\section{Commentary: Age is just an element of the quality of life puzzle following aortic valve replacement}

\author{
Giovanni Mariscalco, $\mathrm{MD}, \mathrm{PhD},{ }^{\mathrm{a}}$ \\ Tatu Juvonen, $\mathrm{MD}, \mathrm{PhD},{ }^{\mathrm{b}, \mathrm{c}}$ and \\ Fausto Biancari, $\mathrm{MD}, \mathrm{PhD}^{\mathrm{c}, \mathrm{d}}$
}

In the current issue of the Journal, Blokzijl and colleagues ${ }^{1}$ reported the impact of surgical aortic valve replacement (SAVR) on physical and mental quality of life in 899 patients. The association between age and health-related quality of life (HRQL) was explored, and, as expected, older patients were identified the most at risk of experiencing deterioration. The authors' analysis might be biased by the large number of nonrespondents ( $29 \%$ of patients), the merging of the Short Form-12 and Short Form-36 health status instrument values, and the relatively low-risk profile of these patients. Furthermore, a decrease in HRQL 1 year after surgery might be simply related to the natural course of advancing age.

The topic of quality of life is a crucial element in assessing the outcome after transcatheter aortic valve replacement (TAVR) or SAVR, although the great majority of studies discuss postoperative morbidity and survival benefits only. ${ }^{2,3}$ The authors correctly commented that well-being and quality of life are likely to be valued more important than quantity of life in the elderly patients. ${ }^{1}$

We definitively agree that expectation on postoperative HRQL needs to be preoperatively emphasized and discussed with patients to tailor the proper procedure for them. ${ }^{1}$ The simple reason is that HRQL is a key element of the TAVR and SAVR effectiveness. Should patients be candidates for TAVR only on the basis of HRQL? Or, is there a specific cohort of patients in whom TAVR should be preferred over SAVR? To answer to these questions,

\footnotetext{
From the a Cardiac Surgery Unit, Glenfield Hospital, University Hospitals of Leicester NHS Trust, Leicester, United Kingdom; ${ }^{b}$ Heart and Lung Center, Helsinki University Hospital, Helsinki, Finland; ' $R$ Research Unit of Surgery, Anesthesia and Intensive Care, University of Oulu, Oulu, Finland; and ${ }^{\mathrm{d}}$ Heart Center, Turku University Hospital and University of Turku, Turku, Finland.

Disclosures: Authors have nothing to disclose with regard to commercial support.

Received for publication Nov 4, 2019; revisions received Nov 4, 2019; accepted for publication Nov 4, 2019; available ahead of print Nov 27, 2019.

Address for reprints: Fausto Biancari, MD, PhD, Turku University Hospital, PO Box 52, 20521 Turku, Finland (E-mail: faustobiancari@yahoo.it).

J Thorac Cardiovasc Surg 2021;161:1213-4

$0022-5223 / \$ 36.00$

Copyright (c) 2019 by The American Association for Thoracic Surgery

https://doi.org/10.1016/j.jtcvs.2019.11.021
}

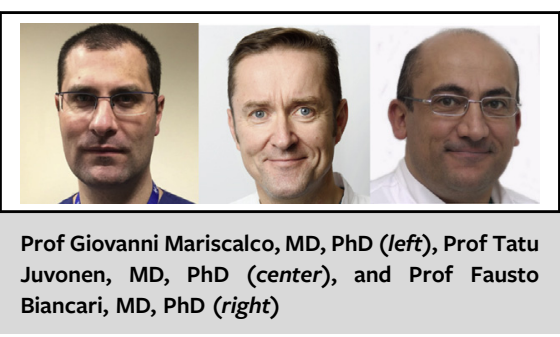

\section{CENTRAL MESSAGE \\ Advanced age is a key factor in influencing the health-related quality of life after surgical aortic valve replacement and may indi- cate the use of new and less- invasive treatment methods.}

we are missing important parameters in the study of Blokzijl and colleagues. ${ }^{1}$ Again, it would have been more appealing to analyze the impact of new and emerging surgical techniques, such as minimally invasive or sutureless approaches, on postoperative HRQL. A recent US investigational device exemption trial of a sutureless aortic bioprosthesis corroborates significant HRQL benefits at 1 year with the sutureless approach. ${ }^{4}$ Minimally invasive approaches (mini-sternotomy or right thoracotomy) proved the same. ${ }^{5}$ Finally, HRQL is impacted by postoperative complications, and SAVR-related complications, such as perioperative bleeding, postoperative acute kidney injury, atrial fibrillation, and stroke, are all associated with worse quality of life after open heart surgery. ${ }^{6,7}$ In the Placement of Aortic Transcatheter Valves 2 (PARTNER 2) trial, when 30-day complications were considered, difference in quality of life between TAVR and TAVI disappeared. ${ }^{2}$ Therefore, the relationship with patient age is only a piece of the puzzle in the understanding the impact of SAVR on HRQL. Certainly, in the present study, the authors have the merit to highlight the HRQL as valuable element in refining the decision making for patients affected by aortic valve disease.

Advanced age is a key factor in influencing the HRQL after SAVR and may indicate the use of new and less-invasive treatment methods. Further studies as the this are definitively deemed to clarify patient populations who would benefit the most from TAVR or SAVR.

\section{References}

1. Blokzijl F, Houterman S, van Straten BHM, Daeter E, Brandon Bravo Bruinsma GJ, Dieperink W, et al. The impact of surgical aortic valve replacement 
on quality of life-a multicenter study. J Thorac Cardiovasc Surg. 2021;161: 1204-10.e7.

2. Baron SJ, Magnuson EA, Lu M, Wang K, Chinnakondepalli K, Mack M, et al. Health status after transcatheter vs. surgical aortic valve replacement in low-risk patients with aortic stenosis. J Am Coll Cardiol. 2019;74: 2833-42.

3. Ando T, Takagi H, Briasoulis A, Grines CL, Afonso L. Comparison of healthrelated quality of life in transcatheter versus surgical aortic valve replacement: a meta-analysis. Heart Lung Circ. 2019;28:1235-45.

4. Suri RM, Javadikasgari H, Heimansohn DA, Weissman NJ, Ailawadi G, Ad N, et al. Prospective US investigational device exemption trial of a sutureless aortic bioprosthesis: one-year outcomes. J Thorac Cardiovasc Surg. 2019;157:1773-82

5. Mariscalco G, Musumeci F. The minithoracotomy approach: a safe and effective alternative for heart valve surgery. Ann Thorac Surg. 2014;97:356-64.

6. Kapadia SR, Huded CP, Kodali SK, Svensson LG, Tuzcu EM, Baron SJ, et al. Stroke after surgical versus transfemoral transcatheter aortic valve replacement in the PARTNER trial. J Am Coll Cardiol. 2018;72:2415-26.

7. Bramer S, ter Woorst FJ, van Geldorp MW, van den Broek KC, Maessen JG Berreklouw E, et al. Does new-onset postoperative atrial fibrillation after coronary artery bypass grafting affect postoperative quality of life? J Thorac Cardiovasc Surg. 2013;146:114-8. 